\title{
Measurement of vocal-tract influence during saxophone performance
}

Gary P. Scavone, Antoine Lefebvre, Andrey R. da Silva, and NFH

Citation: The Journal of the Acoustical Society of America 123, 2391 (2008); doi: 10.1121/1.2839900

View online: http://dx.doi.org/10.1121/1.2839900

View Table of Contents: http://asa.scitation.org/toc/jas/123/4

Published by the Acoustical Society of America 


\title{
Measurement of vocal-tract influence during saxophone performance
}

\author{
Gary P. Scavone, ${ }^{\text {a) }}$ Antoine Lefebvre, and Andrey R. da Silva \\ Computational Acoustic Modeling Laboratory, Centre for Interdisciplinary Research in Music Media \\ and Technology, Music Technology, Schulich School of Music, McGill University, Montreal, Québec, Canada \\ H3A $1 E 3$
}

(Received 5 July 2007; revised 11 January 2008; accepted 13 January 2008)

\begin{abstract}
This paper presents experimental results that quantify the range of influence of vocal tract manipulations used in saxophone performance. The experiments utilized a measurement system that provides a relative comparison of the upstream windway and downstream air column impedances under normal playing conditions, allowing researchers and players to investigate the effect of vocal-tract manipulations in real time. Playing experiments explored vocal-tract influence over the full range of the saxophone, as well as when performing special effects such as pitch bending, multiphonics, and "bugling." The results show that, under certain conditions, players can create an upstream windway resonance that is strong enough to override the downstream system in controlling reed vibrations. This can occur when the downstream air column provides only weak support of a given note or effect, especially for notes with fundamental frequencies an octave below the air column cutoff frequency and higher. Vocal-tract influence is clearly demonstrated when pitch bending notes high in the traditional range of the alto saxophone and when playing in the saxophone's extended register. Subtle timbre variations via tongue position changes are possible for most notes in the saxophone's traditional range and can affect spectral content from at least 800-2000 Hz. (C) 2008 Acoustical Society of America. [DOI: 10.1121/1.2839900]
\end{abstract}

PACS number(s): 43.75.Ef, 43.75.Pq, 43.75.St, 43.75.Yy [NFH] Pages: 2391-2400

\section{INTRODUCTION}

Since the late 1970s, there has been significant interest in understanding the role and influence of a player's vocal tract in wind instrument performance. Acousticians generally agree that, in order for such influence to exist in reed-valve instruments, the player's upstream windway must exhibit input impedance maxima of similar or greater magnitude than those of the downstream air column. ${ }^{1}$ Most musicians concur that they can influence sound via vocal-tract manipulations, though there is less consensus in terms of the extent of such influence or the specifics of how this is done. ${ }^{2}$ A number of previous studies have been reported but attempts to demonstrate and/or quantify vocal-tract influence have not been conclusive. These analyses have been complicated by the fact that measurement of the upstream windway configuration and impedance are difficult under performance conditions.

It is the aim of this study to provide experimental results that substantiate the discussion on the role of vocal tract manipulations in wind instrument performance. The results are obtained using a measurement system that allows the analysis of vocal tract influence in real time during performance.

Most previous acoustical studies of vocal-tract influence have focused on the measurement of the input impedance of players' upstream windways while they simulate or mimic oral cavity shapes used in playing conditions. ${ }^{1,3-6}$ These measurements have then been compared with the input im-

${ }^{a)}$ Electronic mail: gary@ music.mcgill.ca. pedance of the downstream instrument air column to show instances where the vocal tract might be able to influence the reed vibrations. The majority of these investigations are in agreement with regard to the existence of an adjustable upstream wind-way resonance in the range of $500-1500 \mathrm{~Hz}$, which corresponds to the second vocal-tract resonance. ${ }^{3-6}$ On the other hand, musicians do not appear to manipulate the first vocal-tract resonance, which is typically below about $300 \mathrm{~Hz}{ }^{6}$ In Ref. 6, players reported using a fairly stable vocal-tract shape for most normal playing conditions, with upstream manipulations taking place mainly in the altissimo register and for special effects. A brief review of previous studies and a discussion of their limitations is provided by Fritz and Wolfe. ${ }^{6}$

Numerical investigations have also been reported that couple an upstream windway model to a complete wind instrument system. ${ }^{7-10}$ Simplified, single-resonance models of a player's windway have been shown to reproduce bugling, pitchbend, multiphonics, and glissando characteristics in clarinet and saxophone models, effects generally associated with vocal-tract influence. ${ }^{8,9}$

Many performers have used x-ray fluoroscopic or endoscopic approaches to analyze the vocal tract shapes and manipulations used while playing their instruments. ${ }^{2,11-15}$ These studies have reported some general trends in vocal-tract configurations for different registers, produced mainly by variations of the tongue position, but have not well addressed the underlying acoustic principles involved.

A fundamental limitation of previous acoustical investigations is related to the fact that the measurements were not conducted in real time. Subjects were required to mime and 
hold a particular vocal-tract setting for up to $10 \mathrm{~s}$, a task that is likely difficult and uncomfortable for the player. Despite the results of Fritz and Wolfe ${ }^{6}$ that indicate players' have consistent "muscle" (or procedural) memory, it is not clear that subjects can accurately reproduce the exact vocal-tract configurations of interest in this study without playing the instrument because auditory, and perhaps vibrotactile, feedback is important in fine-tuning and maintaining an oral cavity configuration. Further, these methods only provide data for the held setting, without indicating the time-varying characteristics of vocal-tract manipulations. This last issue remains for a recently reported approach that allows the upstream impedance to be measured while the instrument is played. $^{16}$

This paper addresses the previously mentioned limitations by providing a running analysis of vocal-tract influence over time (not solely at discrete moments in time). This is achieved using a measurement system embedded in an $\mathrm{E} b$ alto saxophone that allows a relative comparison of the upstream windway and downstream air column impedances under normal playing conditions. The same approach could also be applied to clarinets, though we chose to concentrate on saxophones given our own playing experience with them.

This paper is organized as follows: Section II describes the measurement approach, including the system and procedures used to evaluate vocal-tract influence. Section III presents the measured data for playing tasks involving traditional and extended registers, pitch bend, bugling, multiphonics, and timbre variation. Finally, Sec. IV concludes with an analysis of the results in the context of saxophone performance practice.

\section{MEASUREMENT APPROACH}

Measurements made for this study were based on continuity of volume flow at the reed junction,

$$
U_{u}=U_{d}=\frac{P_{u}}{Z_{u}}=\frac{P_{d}}{Z_{d}} \Rightarrow \frac{Z_{u}}{Z_{d}}=\frac{P_{u}}{P_{d}},
$$

where $u$ and $d$ subscripts represent upstream and downstream quantities, respectively. This expression is attributed first to Elliot and Bowsher ${ }^{17}$ in the context of brass instrument modeling. This implies that a relative measure of the upstream and downstream impedances can be obtained from the entrance pressures in the player's mouth and the instrument mouthpiece, which is sufficient to indicate when vocal-tract influence is being exerted. That is, it is assumed that the upstream system can be influential when values of $Z_{u}$ are close to or greater than those of $Z_{d}$ and this can be determined from their ratio without knowing the distinct value of each. Because measurements of the mouth and mouthpiece pressures can be acquired while the instrument is being played, this approach allows the player to interact normally with the instrument. Further, as modern computers can calculate and display the pressure spectra in real time, players and researchers can instantly see how vocal tract changes directly affect the upstream impedance.

In this context, the reed is assumed to be primarily controlled by the pressure difference across it and thus, a mea-
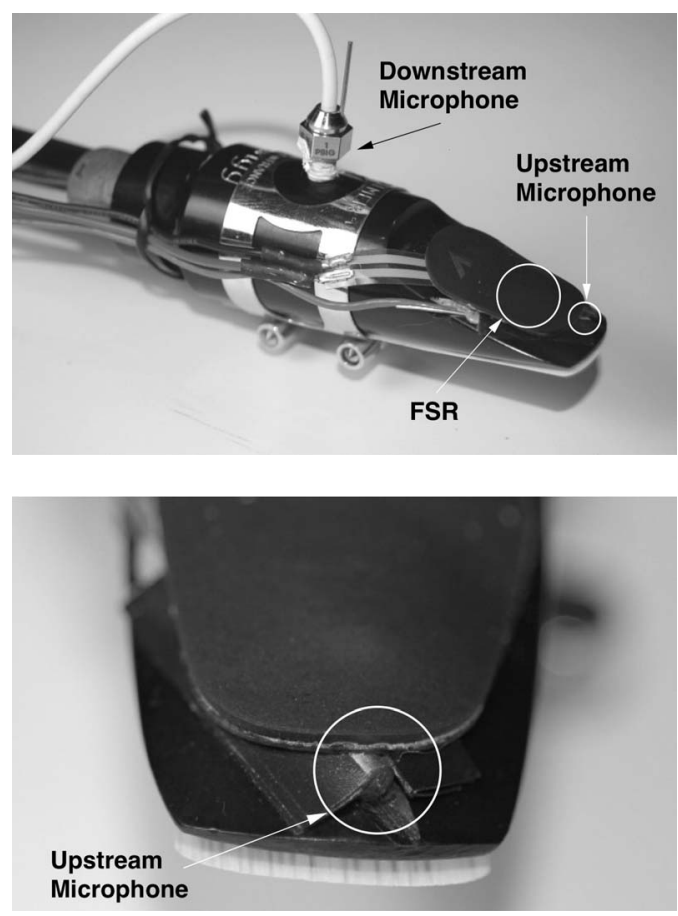

FIG. 1. Saxophone mouthpiece system.

surement of these two pressures can provide a good indication of how the reed oscillations are influenced by the two systems on either side of it. While it may not be possible to use this approach to reconstruct or calculate an upstream impedance characteristic from measurements of $Z_{d}, P_{d}$, and $P_{u}$ (as attempted by Wilson ${ }^{5}$ ), it is valid to indicate instances of upstream influence. This argument ignores the possible effect of hydrodynamic forces on the behavior of the reed due to unsteady flow. ${ }^{18-20}$

\section{A. Measurement system}

The measurement approach used in this study requires the simultaneous acquisition of the "input" pressures on the upstream and downstream sides of the instrument reed under normal playing conditions. Therefore, it was necessary to find a nonintrusive method for measuring pressures in the instrument mouthpiece and the player's mouth near the reed tip. Such measurements are complicated by the fact that the sound pressure levels (SPL) in a saxophone mouthpiece under playing conditions can reach $160 \mathrm{~dB}$ or more ${ }^{21}$ and that the dimensions of the alto saxophone mouthpiece require relatively small microphones to allow normal playing conditions and to avoid interference with the normal reed/ mouthpiece interaction.

After tests with a prototype system, ${ }^{22}$ a special saxophone mouthpiece was developed as shown in Fig. 1. An Endevco 8510B-1 pressure transducer was threaded through the top of the mouthpiece $55 \mathrm{~mm}$ from the mouthpiece tip to obtain internal pressure values. For pressure measurements inside the player's mouth, a groove was carved in the top of the saxophone mouthpiece for an Endevco 8507C-1 miniature pressure transducer of $2.34 \mathrm{~mm}$ diameter such that the transducer tip was positioned $3 \mathrm{~mm}$ behind the front edge of 

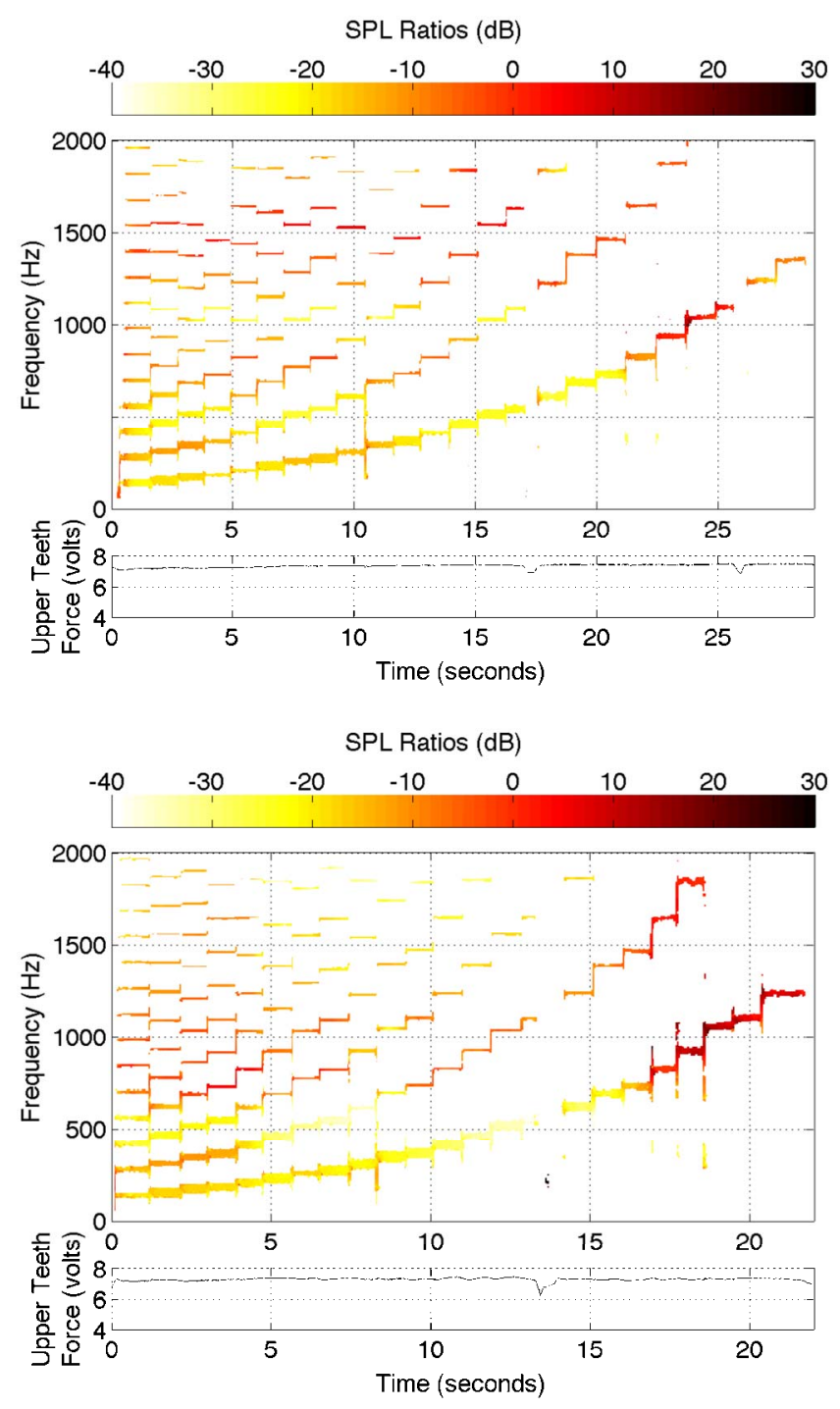

FIG. 2. (Color online) Spectrograms of the SPL ratio between the mouthpiece and the mouth pressures when playing a scale (Subjects A and D, from top to bottom).

the mouthpiece. This position is well within the mouth given that the player's teeth typically rest anywhere from about 13 to $20 \mathrm{~mm}$ from the mouthpiece tip. Both Endevco transducers are rated for maximum SPLs between 170 and $180 \mathrm{~dB}$ and were found to be unaffected by moisture.

Ideally, both microphones would be located at the front edge of the mouthpiece (inside and outside), which represents the input to both the downstream and upstream air columns. Wilson ${ }^{5}$ experimented with two mouthpiece transducer locations on a clarinet and selected the more distant position $(39 \mathrm{~mm})$ because of noise due to unsteady flow nearer the reed tip. The results from a digital waveguide simulation using a cylinder-cone model $^{23}$ suggest that the signal recorded by the $8510 \mathrm{~B}-1$ transducer at a distance of $55 \mathrm{~mm}$ from the tip differs from the downstream input impedance peak values by less than $2 \mathrm{~dB}$ for frequencies up to $1500 \mathrm{~Hz}$ and less than $3.7 \mathrm{~dB}$ for frequencies up to $2000 \mathrm{~Hz}$. Thus, the microphone positioning does not represent a limitation, considering that the frequency range analyzed in this
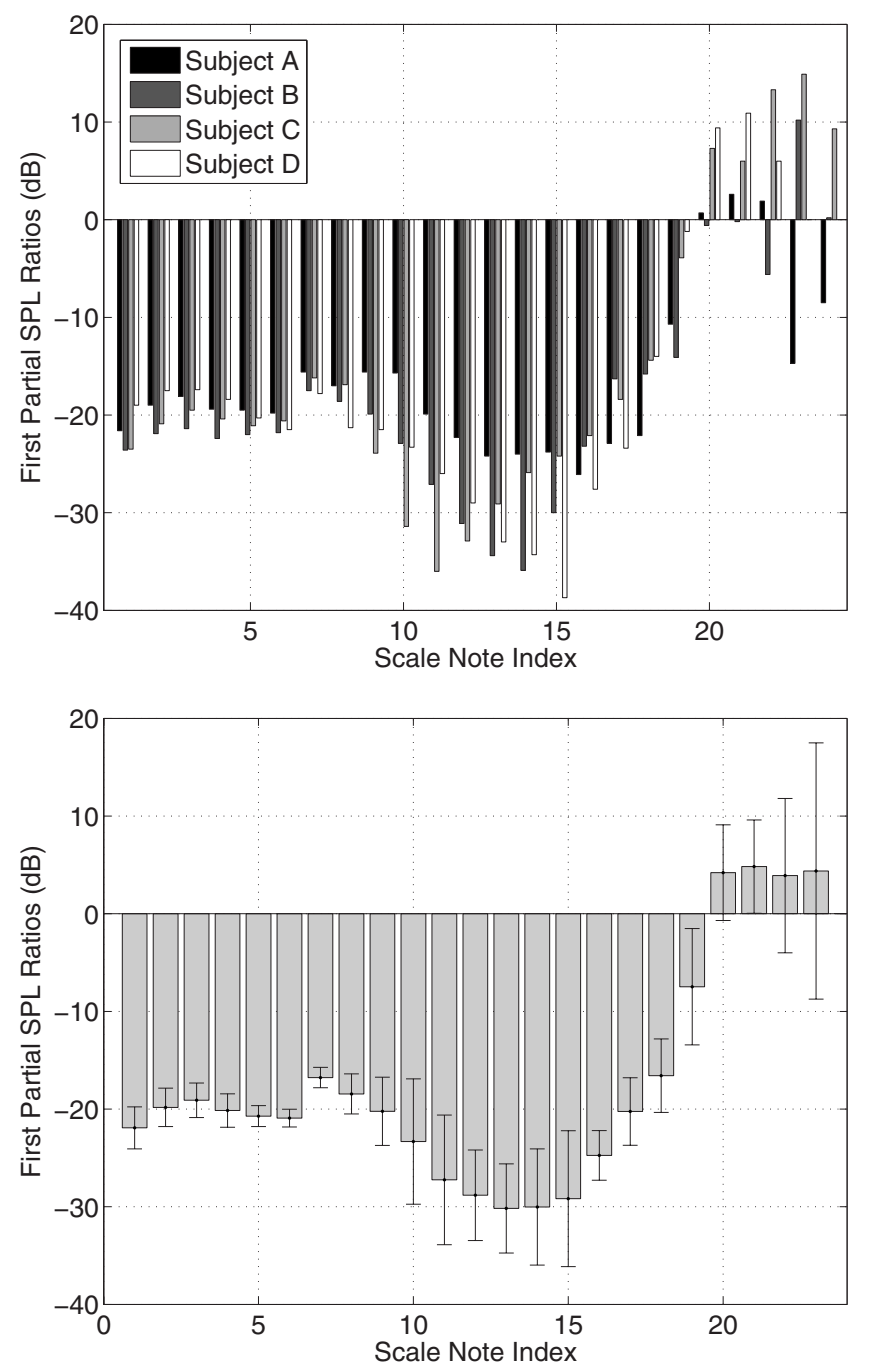

FIG. 3. Average SPL ratios for first partials of scale: individual by subject (top) and for all subjects (bottom).

study does not exceed $2000 \mathrm{~Hz}$ and that we are mainly interested in the use of a vocal-tract resonance that runs from about 500 to $1500 \mathrm{~Hz}$.

The pressure transducers were connected to an Endevco 136 differential voltage amplifier and the signals from there were routed to a National Instruments (NI) PCI-4472 dynamic signal acquisition board. The acquisition card sample rate was set to $12000 \mathrm{~Hz}$. An NI LABVIEW interface was designed to allow real-time display of the spectra of the two pressure signals. The Endevco transducers were calibrated relative to one another prior to the experiment, as described in the Appendix.

To help distinguish between vocal tract and embouchure changes, a small circular (12.7 $\mathrm{mm}$ diameter) force sensing resistor (FSR) made by Interlink Electronics was placed under the cushion on the top of the saxophone mouthpiece to obtain a relative measure of the upper teeth force (see Fig. 1). The time-varying sensor voltages were input to the signal acquisition board for storage and to provide a running display of "embouchure movement" in the LABVIEW interface. Although this setup provided no data on movements of the lower lip, normal embouchure adjustments involve a simul- 

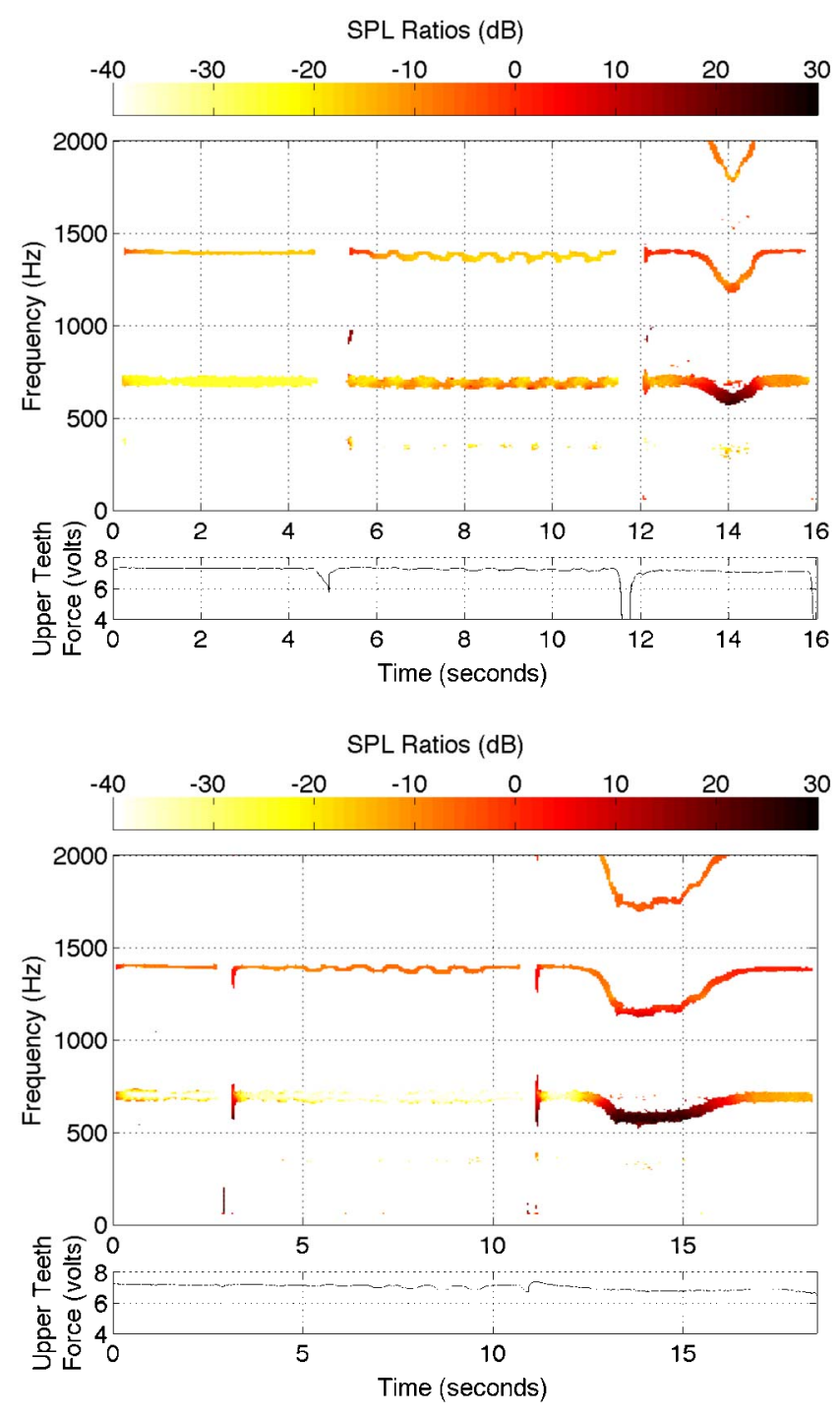

FIG. 4. (Color online) Spectrograms of the SPL ratio between the mouthpiece and the mouth pressures when playing a written D6 without vibrato, with a slow lip vibrato, and bending via vocal tract manipulations (Subjects $\mathrm{B}$ and $\mathrm{D}$, from top to bottom).

taneous variation of both the upper teeth and lower lip. The primary purpose of this sensor was to provide players with visual feedback to help them focus on maintaining a fixed embouchure setting, rather than acquiring an absolute measure of lip or teeth force.

Playing tests were conducted in an IAC (Industrial Acoustics Company) double-walled sound isolation booth to minimize external sound interference. In addition to the mouthpiece described previously, a single Vandoren \#3 (medium hardness) reed and Selmer Super Action Series II alto saxophone (serial number 438024) were used for the entire experiment.

\section{B. Player tests}

Upstream influence was evaluated using the measurement system through a series of playing tests with a group of four professional saxophonists. Subject C was the first author of this paper. The subjects filled out a questionnaire about their saxophone background and experience and were given

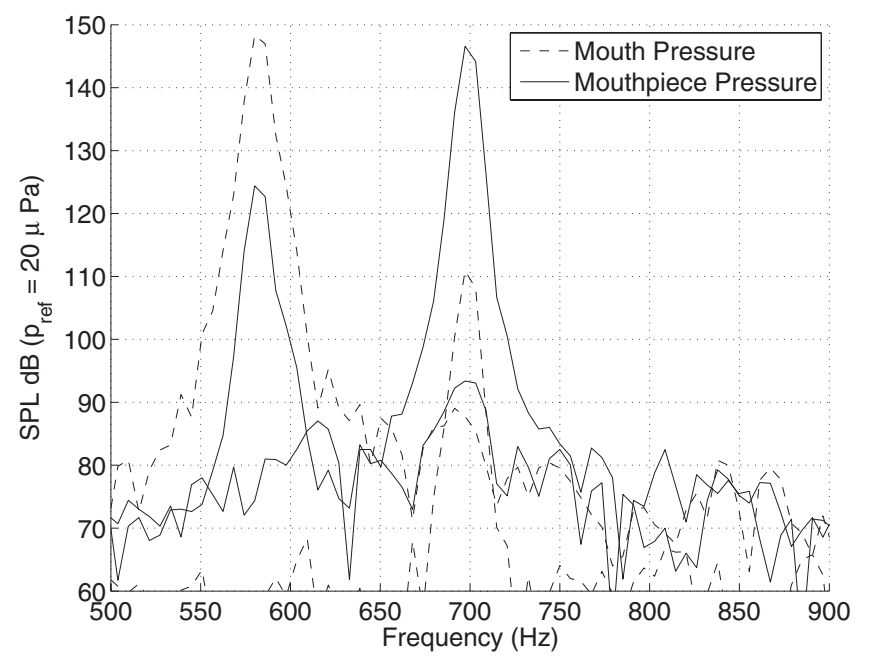

FIG. 5. Overlaid snapshots of the pitch bend spectra on an alto saxophone at the starting frequency $(700 \mathrm{~Hz})$ and at the lowest frequency trajectory $(580 \mathrm{~Hz})$ for Subject D.

about 5 min to become accustomed to the mouthpiece and saxophone setup. They were allowed to practice the requested tasks before the recording began. After the subjects were comfortable with all the tasks, data storage was initiated and each task was performed in sequential order. When subjects had difficulty with a given task, they were allowed to repeat it. A large real-time display of the FSR reading was provided and the subjects were told to avoid making embouchure changes while performing the tasks.

\section{RESULTS}

To examine variations of upstream influence over time, many of the results in the subsequent sections are displayed via spectrograms of the ratio of the SPL in decibels (or power spectral densities) of the mouth and mouthpiece pressures. To reduce artifacts arising from the ratio calculation, spectral bins containing no significant energy in both the upstream and downstream power spectra were masked. The measured upper teeth force is also plotted to indicate the relative steadiness of a player's embouchure setting.

\section{A. Traditional and extended registers}

The traditional range of a saxophone is from written $\mathrm{B}$ b 3-F \#6, which on an alto saxophone corresponds to the frequency range $138.6-880 \mathrm{~Hz}$. Advanced players can play a further octave or more using cross-fingerings, a range referred to as the "altissimo" or extended register. In order to evaluate general player trends over the full range of the instrument, each subject was asked to play an ascending legato written $\mathrm{B} b$ ( $\mathrm{D} b$ concert pitch) scale from the lowest note on the instrument to the highest note that could comfortably be held (which was typically near a written $\mathrm{C} 7$ in the extended register), playing each note for about $0.5 \mathrm{~s}$.

Representative spectrograms of the SPL ratios of upstream and downstream pressures for this task are shown in Fig. 2, as played by Subjects A and D. Breaks in the measured upper teeth force indicate instances where subjects stopped to breath. SPL averages computed at the fundamen- 


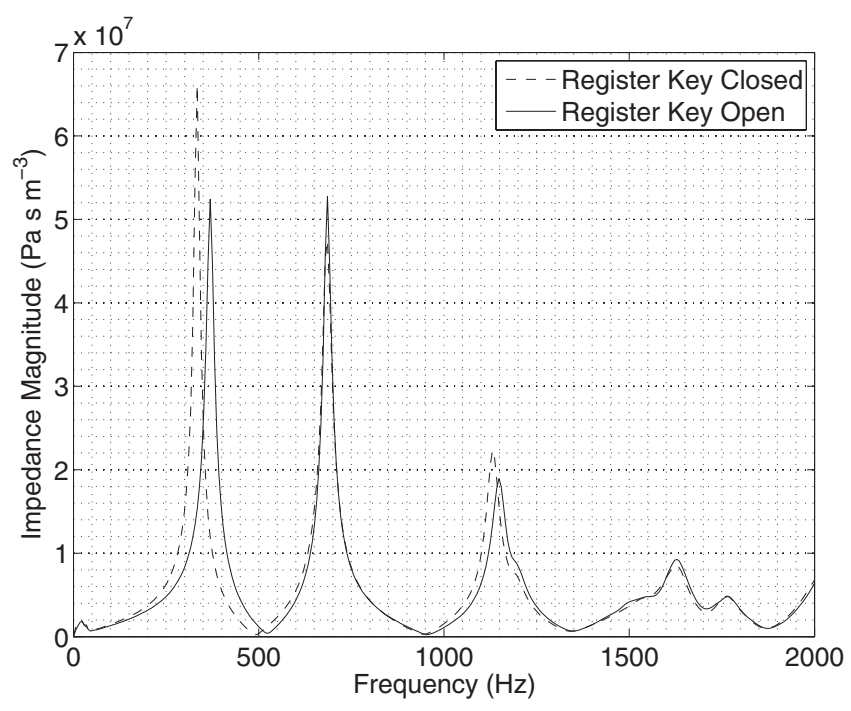

FIG. 6. Input impedance of the alto saxophone for the D6 fingering.

tal frequencies for each scale note are shown in Fig. 3 for each subject and averaged across all subjects. For most notes in the traditional range, the SPL ratios at the fundamental frequencies are below $-20 \mathrm{~dB}$. In other words, pressures in the mouthpiece for these notes are typically 10 times greater than those in the players' mouths. Based on the assumptions outlined in Sec. II, this indicates a similar ratio of input impedance peak levels at the fundamental playing frequencies on either side of the reed and thus minimal upstream influence for notes in this range. These ratios display a local minima centered at the thirteenth note of the scale $(466 \mathrm{~Hz})$, which may be related to the fact that notes in this range are relatively easy to play. The standard deviation of the SPL ratios are shown by the error bars in the lower plot of Fig. 3.

A fairly abrupt change in SPL ratios is evident when subjects prepare to enter the extended register, a result that was also reported by Fritz and Wolfe. ${ }^{6}$ Scale note index 19 in Fig. 3 is the highest note (written F6) in the scale that falls within the traditional register. An alternate fingering exists for F6 on the saxophone that has a playing behavior more like extended register notes (it is based on the use of a third air column partial), though the fingering used by subjects in this study was not specified or recorded. Averaged SPL ratios across all subjects for the extended register notes are between 3 and $5 \mathrm{~dB}$, though the standard deviation is significant. In particular, Subjects A and B show large variations in SPL ratios from note to note in this range, whereas the results for Subjects C and D are more consistent. It should be noted that the task called for a legato scale, or slurring from note to note. Future studies could investigate potential variations of SPL ratios in the extended register when the notes are attacked individually, with or without breaks between each.

It has been suggested by Wilson ${ }^{5}$ that performers might tune upstream resonances with higher harmonics of a played note. There are some instances in Fig. 2 (and the data for the other subjects) where the ratios for upper partials of notes are near $0 \mathrm{~dB}$, typically in the range $600-1600 \mathrm{~Hz}$, though this varies significantly among the subjects. However, no system-
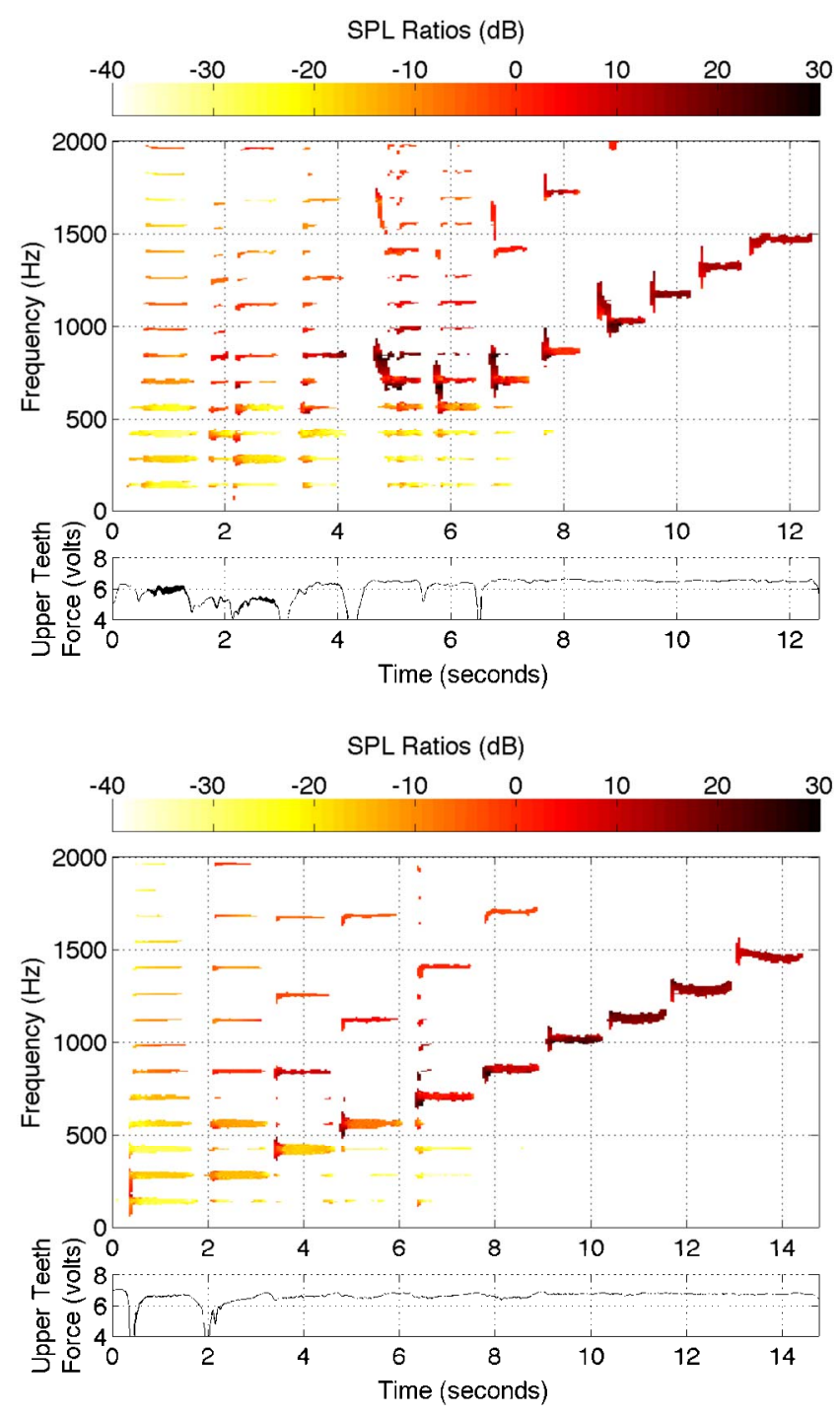

FIG. 7. (Color online) Spectrograms of the SPL ratio between the mouth and mouth piece pressures when performing the bugling task (Subjects B and $\mathrm{C}$, from top to bottom).

atic note-to-note tuning with an upper harmonic was found. It is unlikely that upstream tuning would help stabilize a note unless the fundamental is weak and only one or two higher partials exist below the cutoff frequency of the instrument. That said, variations of upper partial ratios could affect the timbre of the instrument and this is investigated further in Sec. III E.

\section{B. Pitch pending}

Saxophonists make frequent use of pitch bends in their playing, especially in jazz contexts. There are several ways such frequency modifications can be achieved, including lip pressure and tonehole key height changes, as well as vocal tract manipulations. Lip pressure variations, which are used to produce vibrato, affect the average reed tip opening and can yield maximum frequency modulations of about half a semitone. The use of vocal tract manipulations for pitch bend can achieve downward frequency shifts of a musical third or more. Significant upward frequency shifts using lip pressure 

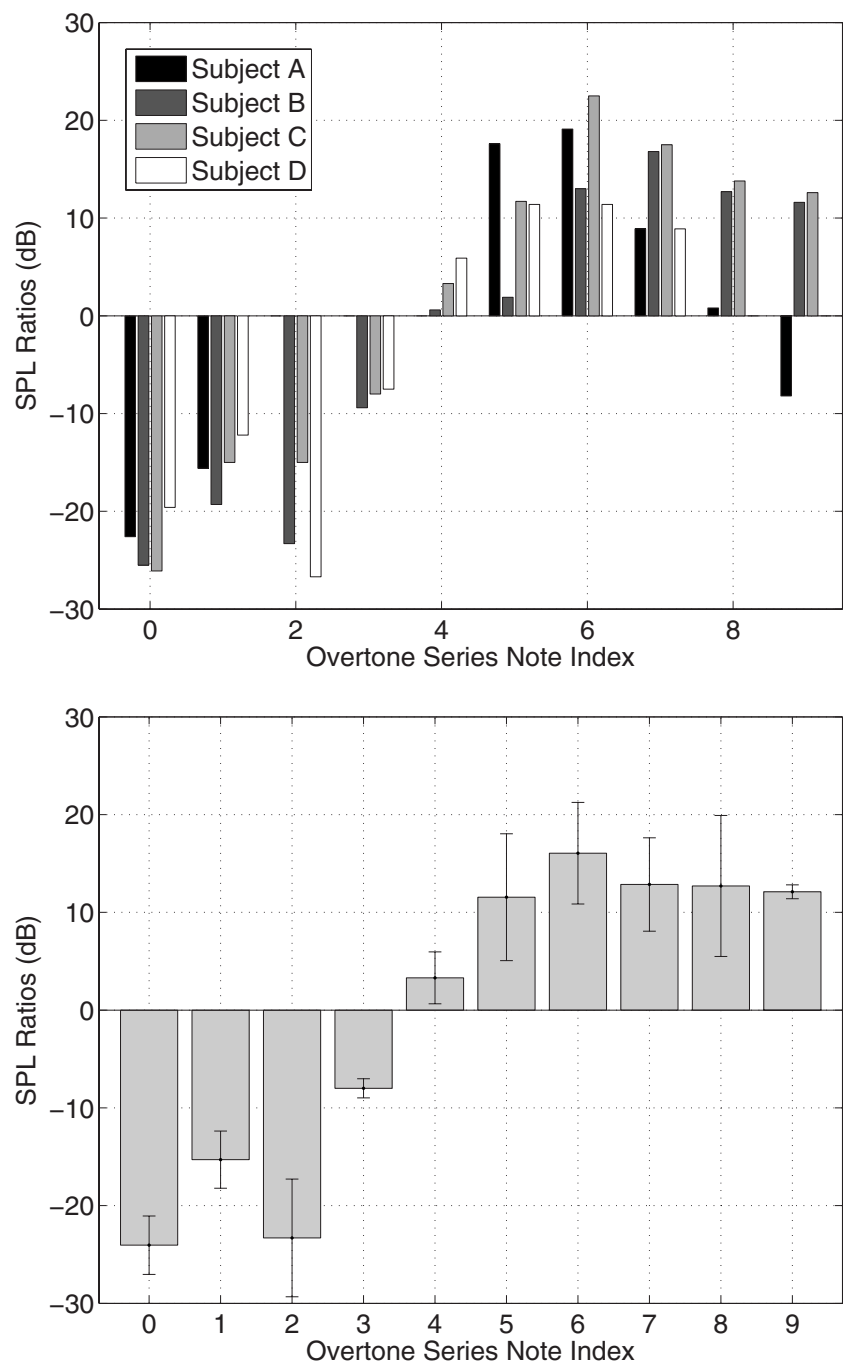

FIG. 8. Average SPL ratios at each overtone series frequency: individual by subject (top) and for all subjects (bottom).

or the vocal tract are not possible. On an alto saxophone, bends produced via vocal-tract manipulations are easiest when starting on notes above concert $\mathrm{E} b 5$. Bends that start above a concert C5 tend to have a lower limit around the C5 frequency $(523 \mathrm{~Hz})$. In other words, the fingered note controls the starting (and highest) frequency of the bend range but the minimum frequency is generally always between 500 and $600 \mathrm{~Hz}$.

Pitch bending has previously been investigated with respect to vocal tract influence. ${ }^{5,6}$ In the present study, subjects were asked to finger a written high D6 $(698 \mathrm{~Hz})$ with the first palm key and to play the note normally, without vibrato, for about $3 \mathrm{~s}$. They were then asked to play the note with a slow vibrato (about $1 \mathrm{~Hz}$ ), modulating the pitch up and down as much as possible using lip pressure only. Finally, subjects were instructed to perform, without varying their lip pressure, a slow downward pitch bend to the lowest note they could comfortably maintain, hold that note for about $1 \mathrm{~s}$, and then bend the note back to the starting D pitch.

Figure 4 shows representative spectrograms of the SPL ratios of upstream and downstream pressures for Subjects B and $\mathrm{D}$ when performing the requested tasks. The average

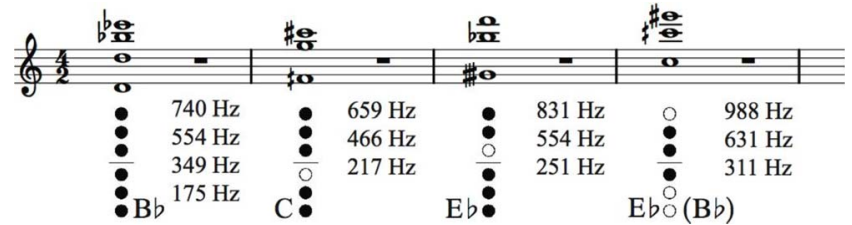

FIG. 9. (Color online) Fingerings and approximate sounding notes (written and frequencies) for four requested multiphonics.

SPL ratio at the fundamental frequency, across all subjects, when played normally without vibrato was $-25 \mathrm{~dB}$, with a standard deviation of 9.3. Subjects B, C, and D demonstrated a consistent vibrato frequency range, using lip pressure variations only, of about $677-700 \mathrm{~Hz}$ (or 54 cents down and about 5 cents up). Subject A's range for the same task was $655-690 \mathrm{~Hz}$, but his SPL fundamental ratios were as high as $3.4 \mathrm{~dB}$ at the vibrato frequency dips, indicating that he used some vocal-tract manipulation as well. For the pitch bend performed without lip pressure variation, the lower frequency limits of the four subjects were 583, 597, 558, and $570 \mathrm{~Hz}$, respectively, with corresponding fundamental frequency SPL ratios of 29.1, 22.7, 30.7, and $25.1 \mathrm{~dB}$. The subjects averaged a frequency drop of 330 cents with a SPL ratio of 26.9 and a standard deviation of 3.7. Snapshots of the upstream and downstream spectra at the starting frequency and lowest frequency trajectory of the pitch bend task for Subject D are overlaid in Fig. 5. At the starting frequency of about $700 \mathrm{~Hz}$, the upstream and downstream SPLs differ by about $-35 \mathrm{~dB}$, while at the bottom of the bend, they differ by about $25 \mathrm{~dB}$.

The input impedance of the alto saxophone used for this study with a D6 fingering is shown in Fig. 6, from which it is clear that the instrument has no strong resonance between 400 and $650 \mathrm{~Hz}$. This measurement was obtained using a two-microphone transfer function technique. ${ }^{24,25}$ Given the fixed fingering and relatively constant lip pressure used by the subjects, as well as the fact that lip pressure variations alone can only produce bends of about 54 cents, the pitch bends of 300 cents and more can only be the result of vocaltract manipulation. The high SPL ratio during the bend indicates that a significantly stronger resonance exists in the players' mouths during the pitch bend than in the downstream air column. The implication is that performers can create a resonance in the upstream windway in the range $700-550 \mathrm{~Hz}$ (for this task) that is strong enough to override the downstream air column and assume control of the reed vibrations.

The upstream resonance frequency is mainly controlled via tongue position variations. The pitch bend is only possible for notes higher in the traditional range, where the air column resonance structure is relatively weak. We speculate that the lower frequency limit on the pitch bend is related to the vocal-tract physiology and players' control of the second upstream resonance within an approximate range of about $520-1500 \mathrm{~Hz}$, which is close to that reported by Benade. ${ }^{3}$ This is corroborated by the fact that a similar lower frequency limit is found when pitch bending on both soprano and tenor saxophones. Informal tests on a $\mathrm{B} b$ clarinet indi- 
cate a greater variance in the lower pitch bend range with different fingerings, though the overall range still falls within the limits mentioned earlier.

\section{C. "Bugling"}

Bugling involves the articulation of the notes of an overtone series while maintaining a fixed low note fingering. Beginning students can normally produce the first and second overtones, sometimes inadvertently while trying to play the fundamental. It typically takes many years of practice to develop the flexibility that allows one to cleanly attack the higher overtones. In this task, subjects were asked to finger a written B b 3 (all holes closed) and to play an overtone series, attacking each note individually.

Representative spectrograms of the SPL ratios for the bugling exercise are shown in Fig. 7, as played by Subjects B and $\mathrm{C}$. Individual subject averages, as well as averages across all subjects, computed at the fundamental frequencies of each overtone are shown in Fig. 8. Subject D did not play overtones 8-9 and Subject A was unable to play overtones 2-4 and 9. Vocal tract influence is not clearly evident until the third overtone, where downstream instrument resonances begin to weaken. In general, it is difficult to play the third overtone without some vocal tract manipulation and it appears that a ratio of about $-7 \mathrm{~dB}$ is sufficient to allow this to happen. It also may be possible that, when playing the third overtone, players reinforce the $1130 \mathrm{~Hz}$ component with an upstream resonance rather than the component at $563 \mathrm{~Hz}$, which falls at the lower end of the adjustable upstream resonance range. Averaging across Subjects B, C, and D, the SPL ratio of the $1130 \mathrm{~Hz}$ component when playing the fundamental of the overtone series is $-8.7 \mathrm{~dB}$. The ratio at this same frequency when playing the third overtone is $4.8 \mathrm{~dB}$.

\section{Multiphonics}

Multiphonics involve oscillations of the reed based on two inharmonic downstream air column resonance frequencies and their intermodulation components. ${ }^{26}$ Two relatively easy and two more difficult multiphonics were chosen for analysis with respect to potential vocal-tract influence. The four multiphonic fingerings and their approximate sounding notes are illustrated in Fig. 9.

Figure 10 shows the SPL ratios for four different multiphonics, as played by Subjects B and D. The sounds produced by the two subjects differed significantly. From the plots, there are more spectral components evident in the sounds of Subject D. We expect that a player can influence the sound quality of a multiphonic by aligning an upstream resonance with one or more components. For example, both subjects appear to reinforce a group of partials in the range $875-1075 \mathrm{~Hz}$ for the last multiphonic. SPL ratio levels for Subject D were, across all tasks, generally higher than those of Subject B. This suggests that Subject D makes use of stronger upstream resonances, which likely explains both the higher ratios for this task, as well as the greater spectral density of the multiphonic sounds.
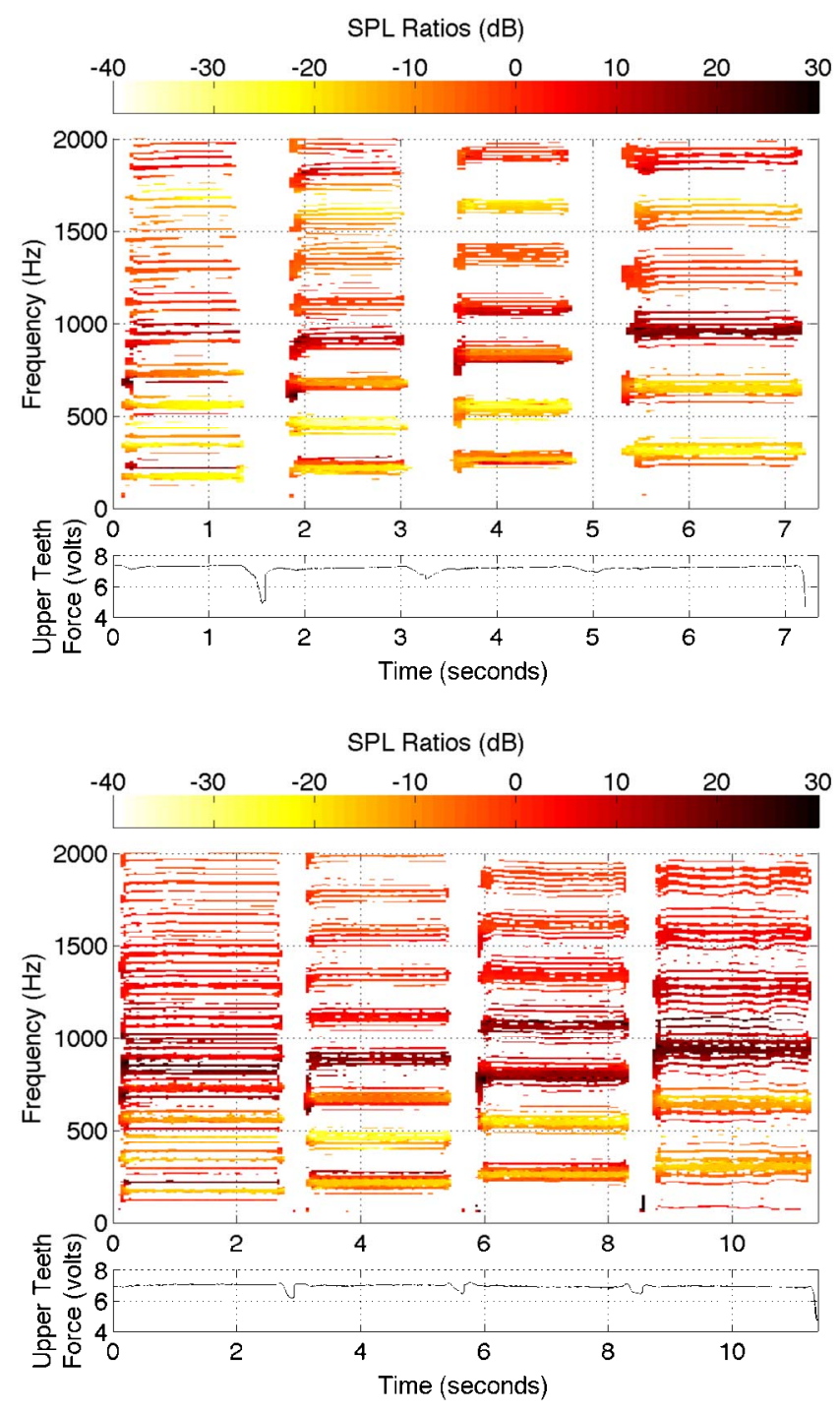

FIG. 10. (Color online) Spectrograms of the SPL ratio between the mouth and mouthpiece pressures when playing four multiphonics (Subjects B and D, from top to bottom).

\section{E. Timbre variations}

In a questionnaire, all subjects indicated that they thought they could influence the sound of the saxophone via vocal-tract variations. They reported using upstream influence to control and adjust tone color (timbre), pitch, and extended register notes. To investigate timbre variations via vocal-tract manipulation, subjects were asked to play a steady written F4 $(207.7 \mathrm{~Hz})$ and to move their tongue periodically toward and away from the reed while maintaining a constant embouchure setting.

Figure 11 shows spectrograms of the SPL ratios resulting from this task, as played by Subjects A and C. Partials four and higher show clear variations in SPL ratios with tongue motion. Snapshots of the mouth and mouthpiece spectra for Subject $\mathrm{C}$ are shown in Fig. 12 at times of 4 and 5 seconds. Although both the upstream and downstream spectra varied with tongue position, the upstream changes were most significant. For example, the downstream SPL of the fourth partial only changes by $+3 \mathrm{~dB}$ between the two 

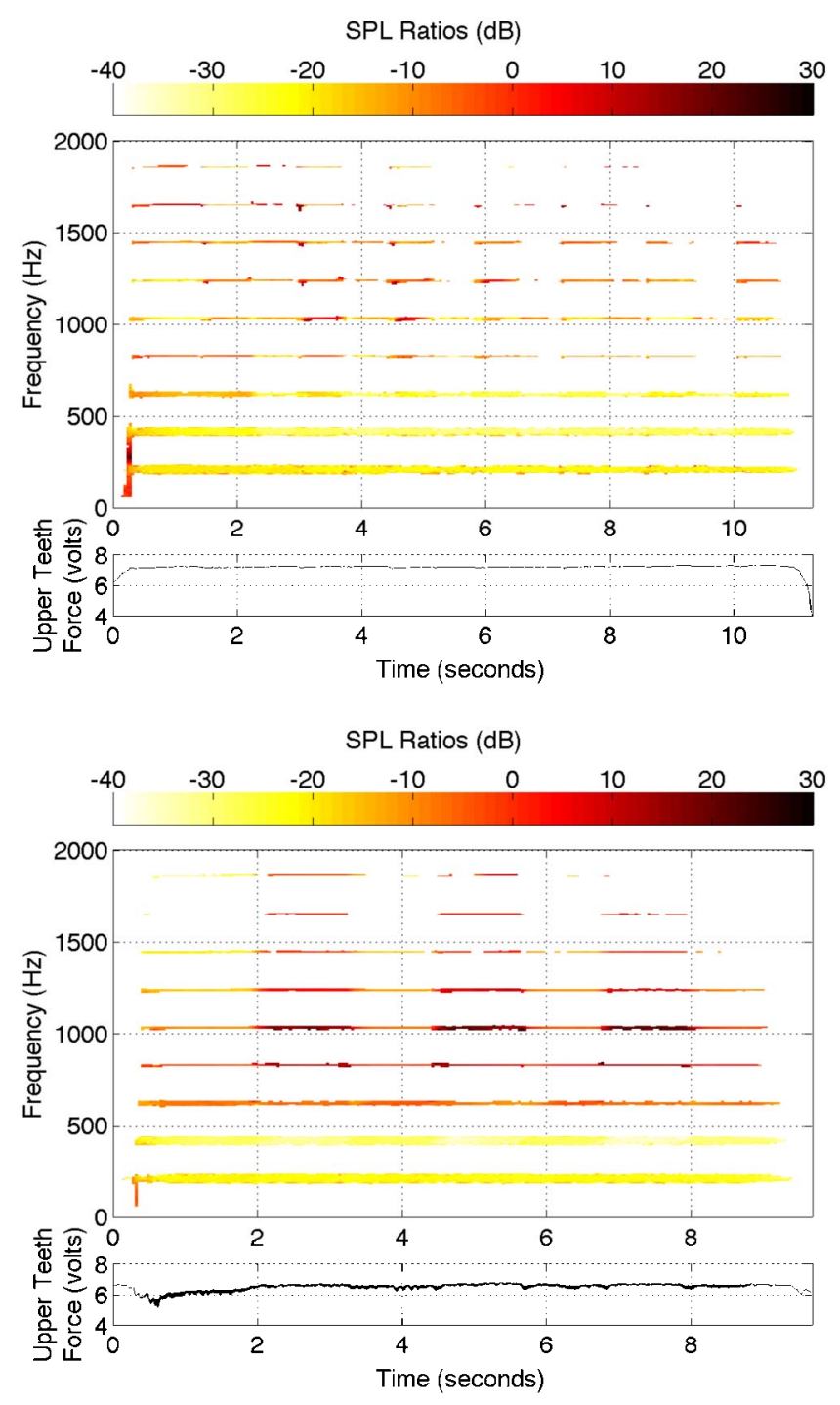

FIG. 11. (Color online) Spectrograms of the SPL ratio between the mouth and mouthypiece pressures when varying tongue position while holding an F3 (Subjects A and C, from top to bottom).

times, whereas the upstream SPL increases by $+13 \mathrm{~dB}$. For this partial and subject, the SPL ratio goes from an average of -0.7 to $9.9 \mathrm{~dB}$, or a difference of $10.6 \mathrm{~dB}$ between the two tongue positions. The change of downstream and upstream SPL for two tongue position extremes is collated for partials 1-9 and Subjects A-C in Fig. 13. Subject D's results showed no clear variation of SPL ratios over time and it is likely this person did not properly understand the requested task. In general, tongue movements toward the reed tended to boost upstream frequency components from about $800 \mathrm{~Hz}$ to at least $2000 \mathrm{~Hz}$. Note that these spectral changes occur simultaneously over a wide frequency range and thus are likely the result of a more wide bandwidth upstream resonance. Below $800 \mathrm{~Hz}$, the effect of the tongue position movement varied significantly among the subjects. It is not possible to say whether these variations were the result of differences in physiology or tongue positions.

\section{DISCUSSION}

Results of the tongue movement task indicate that vocaltract manipulations can be used throughout the playing range
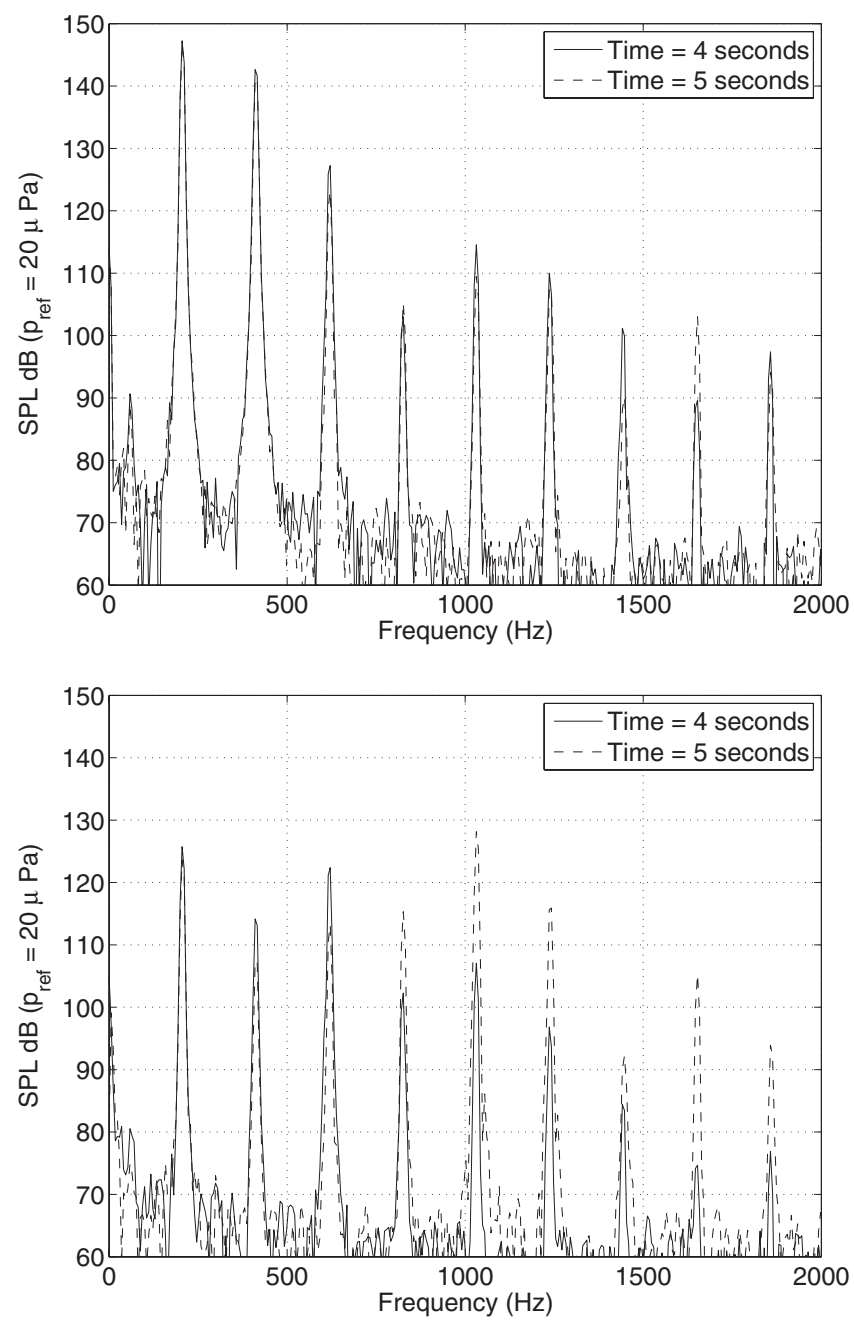

FIG. 12. Snapshots of the mouthpiece (top) and mouth (bottom) spectra for the tongue variation task at times of 4 and $5 \mathrm{~s}$ as played by Subject $\mathrm{C}$.

of the saxophone to produce subtle timbre variations involving frequency components from at least $800-2000 \mathrm{~Hz}$. These timbre variations simultaneously affect partials over a wide frequency range, which implies the use of a relatively wide bandwidth upstream resonance. The pitch bend, extended register, and bugling tasks, however, indicate that vocal-tract influence significant enough to override downstream air column control of reed vibrations is only possible when the downstream system provides weak support of a given note. This is normally the case for notes with fundamental frequencies an octave below the downstream air column cutoff frequency (around $1500 \mathrm{~Hz}$ for the alto saxophone $^{27}$ ) and higher. Thus, significant vocal-tract influence can be exerted for notes near the top of the alto saxophone's conventional range and on into the extended (or altissimo) register. This type of influence makes use of a narrow upstream resonance that the player manipulates to control the fundamental vibrating frequency of the reed.

Various special fingerings are used when playing notes in the saxophone's extended register but these provide only weak downstream support of a note. When students unaccustomed with altissimo register playing try these fingerings, they produce a weak tone lower in the traditional range of 

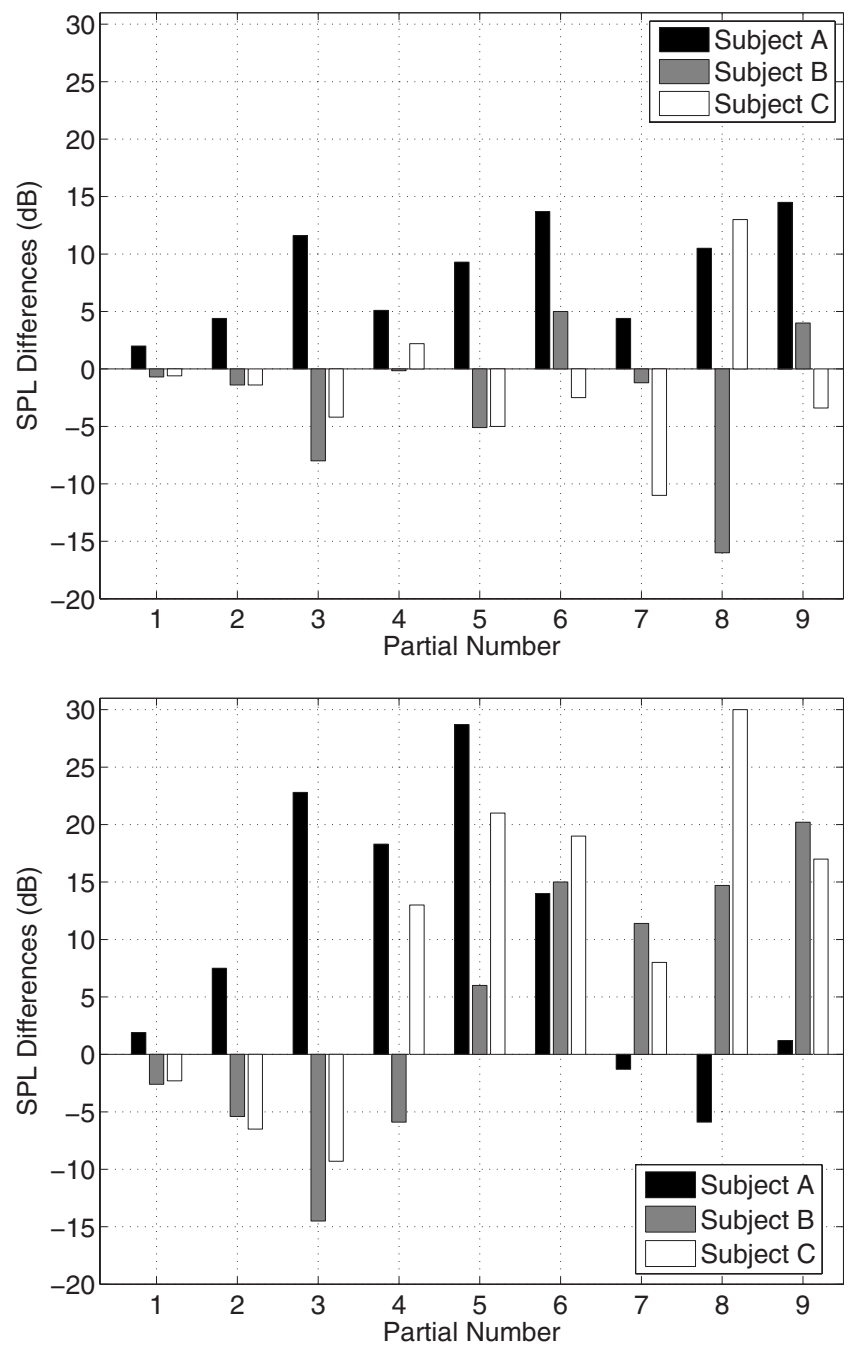

FIG. 13. SPL changes in mouthpiece (top) and mouth (bottom) between two tongue position extremes for partials 1-9 of held F3 (Subjects A, B, and C).

the instrument. From the discussion above, this implies the need for vocal-tract influence when playing in the extended register. There were a few instances when the SPL ratios for Subjects A and $\mathrm{B}$ fell below $0 \mathrm{~dB}$ while playing in this range (see Figs. 3 and 8). This might happen because a given fingering produced a relatively strong downstream resonance at the fundamental playing frequency or it is possible these subjects made embouchure adjustments that were not detected by the FSR on the top of the mouthpiece. The subjects were instructed to avoid making embouchure changes for all tasks in this study. However, it is common for performers to move their lower lip forward, away from the reed tip, in preparation for playing in the saxophone's altissimo register. The authors assume this reduces the reed damping, with a corresponding increase in the reed resonance frequency, and that this may help to maintain normal operation of the reed in its "stiffness controlled" region. As well, extended register playing is generally easier with stiffer reeds. Notes near the top of the extended register, with fundamentals in the range $1400-2000 \mathrm{~Hz}$, may be beyond the range of a high- $Q$ second vocal-tract resonance. It is not clear whether players stabilize these extreme high notes, which are difficult to pro- duce consistently even for professionals, with a vocal-tract resonance and/or by manipulating the reed resonance frequency.

One of the clearest examples of the use of vocal-tract influence involves pitch bending, with downward frequency modulations 5-6 times greater than that possible via lip pressure variations alone. Pitch bends are not possible for notes lower than about a concert C5 $(523 \mathrm{~Hz})$, at the lower extreme of the main adjustable upstream resonance and where several downstream air column resonances can help stabilize a note.

The results of this study are less conclusive with respect to the production of multiphonics. Performers who are unable to play in the extended register of the saxophone normally also have trouble producing the more difficult multiphonics. This would imply the use of an upstream resonance to support one or more intermodulation components. A future study should compare successful and unsuccessful multiphonic attempts for a fixed fingerings in an effort to verify this behavior. There were considerable differences in the sound and quality of the multiphonics produced by the subjects of this study and this is likely related to variations in the upstream system.

Finally, there is a common misconception among some scientists and players that vocal-tract influence is exerted on a nearly continuous basis while playing a single-reed instrument in its traditional range. 5,13 For example, an early study by Clinch et al. ${ }^{13}$ concluded "that vocal tract resonant frequencies must match the frequency of the required notes in clarinet and saxophone performance." Likewise, Wilson ${ }^{5}$ claims that for most tones in analyzed melodic phrases, "the performer's airways were tuned to the first harmonic or to the second harmonic, or there was a resonance aligned with both the first and second harmonics." A related conclusion is made by Thompson ${ }^{28}$ with respect to variations of the reed resonance. These suggestions have no basis in performance practice. Although it is true that effects such as pitch slides common to jazz playing may involve some level of vocaltract influence, most professional musicians use and advocate a relatively fixed vocal-tract shape during normal playing. This behavior is corroborated by Fritz and Wolfe. ${ }^{6}$ It seems likely that players vary their embouchure and perhaps their vocal-tract shape gradually when moving from low to high register notes, but this should be understood to vary with register and not on a note-by-note basis (until one gets to the altissimo register). The results of this study indicate that vocal-tract influence for "normal" playing within the traditional range of the alto saxophone is primarily limited to timbre modification because most of these notes are well supported by the downstream air column.

A website and video demonstrating the measurement system described in this paper is available online. ${ }^{29}$

\section{ACKNOWLEDGMENTS}

The authors thank the anonymous reviewers for their insightful comments and suggestions. They also acknowledge the support of the Natural Sciences and Engineering Research Council of Canada, the Canadian Foundation for 
Innovation, and the Centre for Interdisciplinary Research in Music Media and Technology at McGill University. The doctoral research of the second and third authors is supported by the Fonds Québécois de la Recherche sur la Nature et les Technologies and CAPES (Funding Council of the Brazilian Ministry of Education), respectively. Finally, we would like to thank Bertrand Scherrer for his help in developing the first prototype of the National Instruments LABVIEW measurement system.

\section{APPENDIX: TRANSDUCER CALIBRATION}

A JBL $2426 \mathrm{H}$ compression driver was connected to a steel cylindrical pipe of $150 \mathrm{~mm}$ length and $25.4 \mathrm{~mm}$ diameter. The calibration is valid up to the cutoff frequency of the first higher order mode, which is $f_{c}=1.84 c /(2 \pi a) \approx 8 \mathrm{kHz}$ for a radius $a=12.7 \mathrm{~mm}$ and a speed of sound $c=347 \mathrm{~m} / \mathrm{s}^{30}$ At the far end of this pipe, the two transducers were fit through a cap such that they extended a few millimeters beyond the cap surface. A 60-s noise sequence was played through the system and power spectral densities were determined using a modified averaged periodogram of 1024 data points and 50\% overlap (Hanning windows) at a sampling rate of $48 \mathrm{kHz}$. In order to match fast Fourier transform bins used in the LABVIEW interface and the subsequent data analysis, the calibration data was downsampled to $12 \mathrm{kHz}$. The power spectral densities were computed with the pwelch and cpsd functions in MATLAB. The transfer function relating the gain and phase differences between the microphones was obtained as: ${ }^{31}$

$$
\hat{H}_{12}=\frac{\hat{S}_{22}-\hat{S}_{11}+\sqrt{\left(\hat{S}_{11}-\hat{S}_{22}\right)^{2}+4\left|\hat{S}_{12}\right|^{2}}}{2 \hat{S}_{21}},
$$

where

$$
\begin{aligned}
& \hat{S}_{11}=\operatorname{PWELCH}(\mathrm{P} 1, \operatorname{HANNING}(\mathrm{N}), \mathrm{N} / 2, \mathrm{~N}, \mathrm{FS}), \\
& \hat{S}_{22}=\operatorname{PWELCH}(\mathrm{P} 2, \operatorname{HANNING}(\mathrm{N}), \mathrm{N} / 2, \mathrm{~N}, \mathrm{FS}), \\
& \hat{S}_{12}=\operatorname{CPSD}(\mathrm{P} 1, \mathrm{P} 2, \operatorname{HANNING}(\mathrm{N}), \mathrm{N} / 2, \mathrm{~N}, \mathrm{FS}),
\end{aligned}
$$

and

$$
\hat{S}_{21}=\operatorname{CPSD}(\mathrm{P} 2, \mathrm{P} 1, \operatorname{HANNING}(\mathrm{N}), \mathrm{N} / 2, \mathrm{~N}, \mathrm{FS}) .
$$

A similar calibration technique was previously reported by Seybert and Ross. ${ }^{24}$

${ }^{1}$ J. Backus, "The effect of the player's vocal tract on woodwind instrument tone," J. Acoust. Soc. Am. 78, 17-20 (1985).

${ }^{2}$ M. Watkins, "The saxophonist's vocal tract. 1," Saxophone Symp. 27, 51-78 (2002).

${ }^{3}$ A. H. Benade, "Air column, reed, and player's windway interaction in musical instruments," in Vocal Fold Physiology, Biomechanics, Acoustics, and Phonatory Control, edited by I. R. Titze and R. C. Scherer (Denver Center for the Performing Arts, Denver, CO, 1985), Chap. 35, pp. 425452.

${ }^{4}$ P. L. Hoekje, "Intercomponent energy exchange and upstream/downstream symmetry in nonlinear self-sustained oscillations of reed instruments," Ph.D. thesis, Case Western Reserve University, Cleveland, OH, 1986.

${ }^{5}$ T. D. Wilson, "The measured upstream impedance for clarinet performance and its role in sound production," Ph.D. thesis, University of Wash- ington, Seattle, WA, 1996.

${ }^{6} \mathrm{C}$. Fritz and J. Wolfe, "How do clarinet players adjust the resonances of their vocal tracts for different playing effects?," J. Acoust. Soc. Am. 118, 3306-3315 (2005).

${ }^{7}$ S. D. Sommerfeldt and W. J. Strong, "Simulation of a player-clarinet system,” J. Acoust. Soc. Am. 83, 1908-1918 (1988).

${ }^{8}$ R. Johnston, P. G. Clinch, and G. J. Troup, "The role of the vocal tract resonance in clarinet playing," Acoust. Aust. 14, 67-69 (1986).

${ }^{9}$ G. P. Scavone, "Modeling vocal-tract influence in reed wind instruments," in Proceedings of the 2003 Stockholm Musical Acoustics Conference, Stockholm, Sweden, pp. 291-294.

${ }^{10} \mathrm{P}$. Guillemain, "Some roles of the vocal tract in clarinet breath attacks: Natural sounds analysis and model-based synthesis," J. Acoust. Soc. Am. 121, 2396-2406 (2007).

${ }^{11}$ R. L. Wheeler, "Tongue registration and articulation for single and double reed instruments," Natl. Assoc. College Wind Percussion Instruct. J. 22, 3-12 (1973).

${ }^{12}$ W. E. J. Carr, "A videofluorographic investigation of tongue and throat positions in playing flute, oboe, clarinet, bassoon, and saxophone," Ph.D. thesis, University of Southern California, Los Angeles, CA, 1978.

${ }^{13}$ P. G. Clinch, G. J. Troup, and L. Harris, "The importance of vocal tract resonance in clarinet and saxophone performance: A preliminary account," Acustica 50, 280-284 (1982).

${ }^{14} \mathrm{~J}$. T. Peters, "An exploratory study of laryngeal movements during performance on alto saxophone," Master's thesis, North Texas State University, Denton, TX, 1984.

${ }^{15} \mathrm{M}$. Patnode, "A fiber-optic study comparing perceived and actual tongue positions of saxophonists successfully producing tones in the altissimo register," Ph.D. thesis, Arizona State University, 1999.

${ }^{16}$ J.-M. Chen, J. Smith, and J. Wolfe, "Vocal tract interactions in saxophone performance," in Proceedings of the International Symposium on Musical Acoustics, Barcelona, Spain, 2007.

${ }^{17}$ S. Elliott and J. Bowsher, "Regeneration in brass wind instruments," J. Sound Vib. 83, 181-217 (1982).

${ }^{18}$ A. R. da Silva, G. P. Scavone, and M. van Walstijn, "Numerical simulations of fluid-structure interactions in single-reed mouthpieces," J. Acoust. Soc. Am. 122, 1798-1809 (2007).

${ }^{19}$ J. van Zon, A. Hirschberg, J. Gilbert, and A. Wijnands, "Flow through the reed channel of a single reed instrument," J. Phys. (Paris), Colloq. 54, C2 821-824 (1990).

${ }^{20}$ A. Hirschberg, R. W. A. van de Laar, J. P. Marrou-Maurières, A. P. J. Wijnands, H. J. Dane, S. G. Kruijswijk, and A. J. M. Houtsma, "A quasistationary model of air flow in the reed channel of single-reed woodwind instruments," Acustica 70, 146-154 (1990).

${ }^{21} \mathrm{X}$. Boutillon and V. Gibiat, "Evaluation of the acoustical stiffness of saxophone reeds under playing conditions by using the reactive power approach," J. Acoust. Soc. Am. 100, 1178-1889 (1996).

${ }^{22}$ G. P. Scavone, "Real-time measurement/viewing of vocal-tract influence during wind instrument performance (A)," J. Acoust. Soc. Am. 119, 3382 (2006).

${ }^{23}$ G. P. Scavone, "Time-domain synthesis of conical bore instrument sounds," in Proceedings of the 2002 International Computer Music Conference, Göteborg, Sweden, pp. 9-15.

${ }^{24}$ A. Seybert and D. Ross, "Experimental determination of acoustic properties using a two-microphone random excitation technique," J. Acoust. Soc. Am. 61, 1362-1370 (1977).

${ }^{25}$ A. Lefebvre, G. P. Scavone, J. Abel, and A. Buckiewicz-Smith, "A comparison of impedance measurements using one and two microphones," in Proceedings of the International Symposium on Musical Acoustics, Barcelona, Spain, 2007.

${ }^{26}$ J. Backus, "Multiphonic tones in the woodwind instrument," J. Acoust. Soc. Am. 63, 591-599 (1978).

${ }^{27}$ A. H. Benade and S. J. Lutgen, "The saxophone spectrum," J. Acoust. Soc. Am. 83, 1900-1907 (1988).

${ }^{28}$ S. C. Thompson, "The effect of the reed resonance on woodwind tone production,” J. Acoust. Soc. Am. 66, 1299-1307 (1979).

${ }^{29}$ G. P. Scavone, http://www.music.mcgill.ca/ gary/vti/, 2007 (last viewed 11 January 2008).

${ }^{30}$ N. H. Fletcher and T. D. Rossing, The Physics of Musical Instruments (Springer, New York, 1991).

${ }^{31}$ J. H. P. R. White and M. H. Tan, "Analysis of the maximum likelihood, total least squares and principal component approaches for frequency response function estimation,” J. Sound Vib. 290, 676-689 (2006). 